\title{
Early Interleukin 4-Dependent Response Can Induce Airway Hyperreactivity before Development of Airway Inflammation in a Mouse Model of Asthma
}

\author{
Yasuo To, Makoto Dohi, Ryoichi Tanaka, Atsushi Sato, Kazuyuki Nakagome, and \\ Kazuhiko Yamamoto \\ Department of Allergy and Rheumatology, Graduate School of Medicine, University of Tokyo, Tokyo, Japan
}

\begin{abstract}
SUMMARY: In experimental models of bronchial asthma with mice, airway inflammation and increase in airway hyperreactivity (AHR) are induced by a combination of systemic sensitization and airway challenge with allergens. In this report, we present another possibility: that systemic antigen-specific sensitization alone can induce AHR before the development of inflammation in the airway. Male BALB/c mice were sensitized with ovalbumin (OVA) by a combination of intraperitoneal injection and aerosol inhalation, and various parameters for airway inflammation and hyperreactivity were sequentially analyzed. Bronchial response measured by a noninvasive method (enhanced pause) and the eosinophil count and interleukin (IL)-5 concentration in bronchoalveolar lavage fluid (BALF) gradually increased following the sensitization, and significant increase was achieved after repeated OVA aerosol inhalation along with development of histologic changes of the airway. In contrast, AHR was already significantly increased by systemic sensitization alone, although airway inflammation hardly developed at that time point. BALF IL-4 concentration and the expression of IL-4 mRNA in the lung reached maximal values after the systemic sensitization, then subsequently decreased. Treatment of mice with anti-IL-4 neutralizing antibody during systemic sensitization significantly suppressed this early increase in AHR. In addition, IL-4 gene-targeted mice did not reveal this early increase in AHR by systemic sensitization. These results suggest that an immune response in the lung in an early stage of sensitization can induce airway hyperreactivity before development of an eosinophilic airway inflammation in BALB/c mice and that IL-4 plays an essential role in this process. If this early increase in AHR does occur in sensitized human infants, it could be another therapeutic target for early prevention of the future onset of asthma. (Lab Invest 2001, 81:1385-1396).
\end{abstract}

$A$ fter exposure to allergen(s), atopic bronchial asthma is characterized by airway inflammation and increased serum immunoglobulin (lg) E levels together with increased airway hyperreactivity (AHR) in response to specific allergens and nonspecific stimuli (Burrows et al, 1989; Sears et al, 1991). In the process of airway inflammation, many kinds of inflammatory cells, such as mast cells (Ying et al, 1997), eosinophils (Lamkhioued et al, 1997), and T lymphocytes (Crimi et al, 1997; De Sanctis et al, 1997), are involved. In addition, various cytokines and growth factors produced by these cells, such as interleukin (IL)-4 (Leonard et al, 1997; Shi et al, 1998a), IL-5 (Shi et al, 1998b; Till et al, 1998), IL-10 (Borish et al, 1996; Robinson et al, 1996), IL-12 (Van Der Pouw Kraan et al, 1997), and IL-13 (Humbert et al, 1997), may play important roles in the disease process. IL-5 and eosinophils have been recently specifically implicated as key contributors to the development of allergic airway inflammation.

\section{Received May 7, 2001}

This work was partly supported by the Manabe Medical Foundation and by a grant from the Ministry of Health, Labor, and Welfare (No. 13670592). Address reprint requests to: Dr. Makoto Dohi, Department of Allergy and Rheumatology, Graduate School of Medicine, University of Tokyo, 7-3-1 Hongo, Bunkyo-ku, Tokyo 113-8655, Japan. E-mail: DOHI-PHY@h.u-tokyo.ac.jp
The predominance of Th2 phenotype of lymphocyte over Th1 phenotype from a very early stage of life has recently been highlighted, and this polarization is likely to have some relation to the future development of allergic diseases such as asthma (Gern et al, 1999). This Th2-polarized immunity in infancy is accelerated by repeated exposures to allergen(s) and is considered to be one of the predisposing factors leading to atopic asthma with apparent inflammation later in life (Holt et al, 1999). These findings strongly underline the importance of studying not only the phase in which airway inflammation is fully developed, but also the pre- or early-inflammatory phase in which progress toward the onset of symptoms is silently underway.

Animal models of asthma are very useful tools for analyzing the process leading to allergic reactions in the airways. Many of the recent studies have used mouse models. For example, recent studies have elucidated the role of Th1 and Th2 cells in the development of allergic reactions (Hansen et al, 1999; Randolph et al, 1999a, 1999b). So far, analyses using mice have mainly focused on the phase of airway inflammation with pathologic changes of bronchial tissue. On the other hand, quite a few studies have been reported elucidating the early immune response before the development of prominent airway inflammation. Zhang and co-workers (1997b) reported that ip sensitization with ovalbumin (OVA) allergen twice, 
along with one intranasal challenge, can induce airway eosinophilia and AHR, but they did not study the results with systemic sensitization alone. No other report has elucidated this issue.

Recently, we reported a noninvasive system for potentially measuring airway function in a mouse experimental model of asthma (Dohi et al, 1999). This system allows us to monitor the bronchial response of an individual mouse to an allergen repeatedly and noninvasively throughout the course of the experiment. This system could clarify the relationship between development of sensitization to an allergen and the beginning of bronchial response and increase in AHR.

The purpose of the present study is to elucidate the relationships among various parameters essential for development of allergic asthma, such as AHR, Th2 cytokine production, airway inflammation, and tissue damage during the process of sensitization and progression of airway inflammation. Using a combination with our noninvasive measuring system and conventional sampling, we analyzed the changes in these parameters over a period of time with systemic and airway sensitization. We found that AHR could be induced from an early stage before the development of eosinophilic airway inflammation and, further, that IL-4 plays a key role in this process.

\section{Results}

\section{Change in Noninvasive Enhanced Pause Value}

Male BALB/c mice (6 weeks of age) were immunized by a combination of OVA $(2 \mu \mathrm{g})$ and aluminum hydroxide (alum, $2 \mathrm{mg}$ ) by ip injection on Day 0, and then again on Day 11. Control mice received saline injection instead of the OVA/alum solution. On Day 18, an aerosolized solution of $3 \%$ OVA diluted in PBS was administered for 10 minutes. In a full protocol OVA inhalation was carried out for 5 consecutive days from Day 18 to Day 22. Control mice inhaled PBS under the same conditions. Ninety-six hours after the fifth OVA challenge (on Day 26), a final OVA inhalation challenge (the sixth OVA challenge) was given in the same way, and the control group was challenged with PBS. During sensitization, serial changes in noninvasive enhanced pause (Penh) value of the same mice were obtained following the experimental protocol on Day 0 (before the first systemic immunization), on Day 18 (one week after the second systemic immunization and just before the first aerosol inhalation), on Day 21 (24 hours after the third aerosol challenge), and on Day 27 (24 hours after the final OVA provocation). Figure 1 shows the results. In the saline/PBS-treated control group Penh did not show any significant change throughout the time course. In the OVA-treated mice, Penh increased gradually following the sensitization. On Day 18, after systemic sensitization and just before inhalation, Penh did not show any significant increase compared with the baseline value of Day 0. On Day 21, after 3 days of inhaled OVA, Penh increased significantly $(p<0.01$ vs Day 0 and $p<0.05$ vs saline/PBS
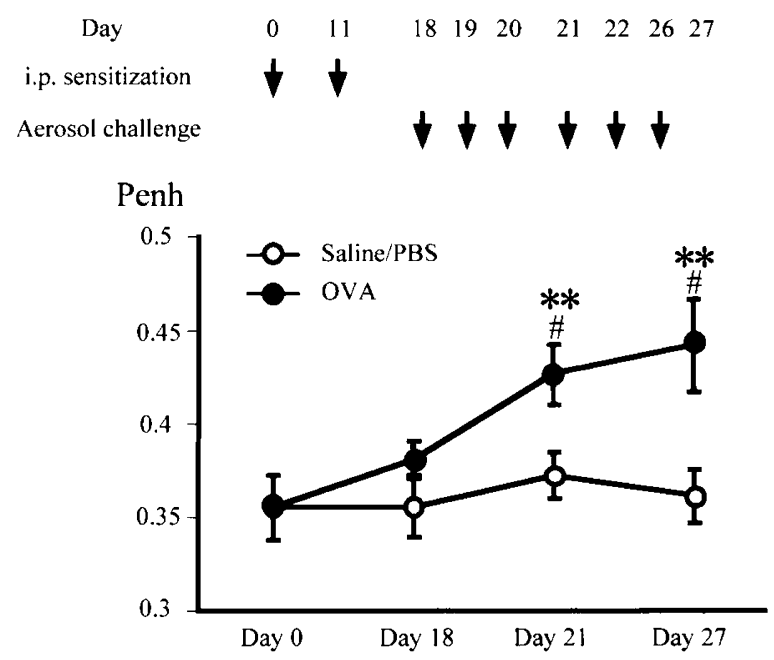

Figure 1.

Change in enhanced pause (Penh) in the ovalbumin (OVA)-treated group and the control group. Mice were sensitized with OVA or saline on Day 0 and Day 11 and challenged with 3\% OVA in PBS or PBS alone from Days 18 to 22 and on Day 26, as described in "Materials and Methods." Bronchial response at each time point was measured repeatedly with the noninvasive Penh method in each mouse. Penh was measured on Day 0 (before systemic sensitization), Day 18 (a week after the second systemic sensitization and just before aerosol inhalation), Day 21 (after 3 days of inhalation challenge), and Day 27 (24 hours after the final OVA inhalation). Data represent the mean \pm SEM for groups of seven mice. ${ }^{* *} p<0.01$ compared with baseline Penh value of Day 0 ; $\# p<$ 0.05 compared with Penh of the same time point in the control saline/PBS group (ANOVA).

control). Penh increased further and reached a maximal value 24 hours after the final OVA inhalation on Day 27.

\section{Change in AHR to Methacholine}

Next we examined the change in AHR following sensitization. Nonspecific AHR to methacholine (Mch) was measured with the Penh system essentially using the noninvasive Penh method reported by Lee and co-workers (1997). The geometric mean of $\mathrm{PC}_{200} \mathrm{Mch}$ on Day 0 was $16,035 \pm 1034 \mu \mathrm{g} / \mathrm{ml}$ (Fig. 2). A slight increase in AHR was observed in the control saline/ PBS-treated group on Day $18\left(\mathrm{PC}_{200}\right.$ Mch was 10,984 $\pm 1156 \mu \mathrm{g} / \mathrm{ml}, n=7$ ), but it was not significantly different from the baseline value on Day 0 , and AHR did not increase further thereafter in this control group. In the OVA-treated mice, $\mathrm{PC}_{200}$ Mch on Day 18 was $5632 \pm 741 \mu \mathrm{g} / \mathrm{ml}(n=7)$. This was significantly lower than the $\mathrm{PC}_{200}$ Mch on Day $0(p<0.01)$ and significantly lower than the $\mathrm{PC}_{200} \mathrm{Mch}$ in the control group on the same day (Day 18). Therefore, in the OVAtreated group, systemic sensitization alone induced a significant increase in AHR. Significant increase in the AHR was also detected on Days 21 and 27 in the OVA-treated group. The $\mathrm{PC}_{200}$ Mch was $6638 \pm 834$ $\mu \mathrm{g} / \mathrm{ml}(n=7)$ on Day 21 and $5769 \pm 966 \mu \mathrm{g} / \mathrm{ml}(n=$ 7 ) on Day 27 ( $<0.01$ vs that of Day 0 , respectively). Immunization with saline plus alum showed a tendency to induce a slight increase in AHR on Day 18 $\left(\mathrm{PC}_{200}\right.$ Mch was $\left.7,691 \pm 1348 \mu \mathrm{g} / \mathrm{ml}, n=4\right)$, but the increase was not statistically significant. Therefore, 


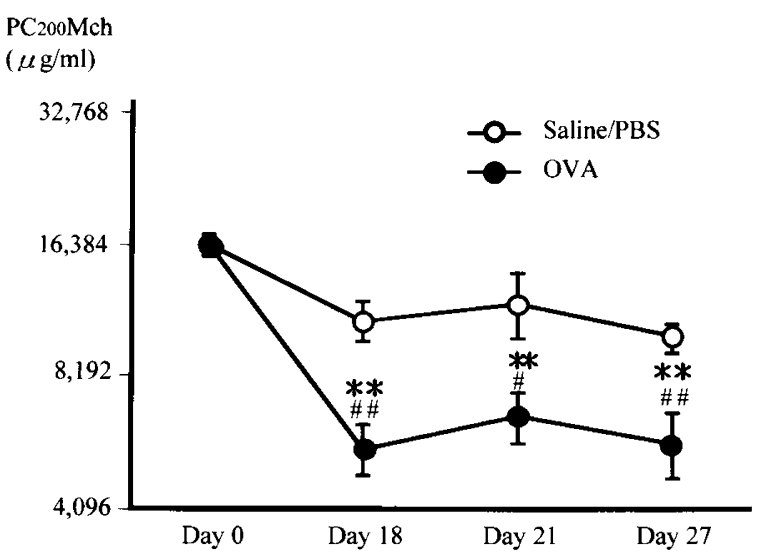

Figure 2.

Change in airway hyperreactivity (AHR) to methacholine (Mch) following sensitization. AHR to Mch was measured on Day 0 (before systemic sensitization), Day 18 (after systemic sensitization, and just before inhalation challenge), Day 21 (after 3 days of inhalation challenge), and Day 27 (24 hours after the final OVA provocation). Each group of mice was subjected to Mch inhalations at each time point. After confirming that physiologic saline alone did not increase the baseline Penh value, the mice received serial inhalations of increasing concentrations of Mch (1000, 3000, 10,000, 20,000, and 30,000 $\mu \mathrm{g} / \mathrm{ml}$ in physiologic saline) for 2.5 minutes. Penh was measured and recorded immediately after each inhalation. The concentration of Mch required to provoke a $100 \%$ increase in the Penh value over the value after saline inhalation was calculated from the semi-log scale dose response curve and expressed as $\mathrm{PC}_{200} \mathrm{Mch}(\mu \mathrm{g} / \mathrm{ml})$. Data are presented as geometric mean $\pm \mathrm{SEM}$ for seven mice for each time point per group. ${ }^{* *} p<0.01$ compared with baseline value on Day $0 ; \# p<0.05$ and \#\#p<0.01 compared with $\mathrm{PC}_{200} \mathrm{Mch}$ at the same time point in the control group (ANOVA).

the increase in the AHR on Day 18 was due to antigen-specific systemic sensitization with the OVA allergen. We repeated the same experiment four times and confirmed the reproducibility of the result.

\section{BALF Cell Analysis}

To elucidate whether the increase in AHR in the early stage of sensitization would be induced by airway inflammation, we analyzed bronchoalveolar lavage fluid (BALF) findings following the sensitization (Fig. 3). In the control group, no significant changes in the cell number or cell differentials were observed throughout the time period. Most of the cells in BALF on Day 0 were macrophages, and lymphocytes and eosinophils were hardly detected. On Day 18, a slight increase in total cell and macrophage number was observed in the OVA-treated mice, but no significant difference was detected. A few eosinophils were also observed $\left(0.02 \pm 0.01 \times 10^{5}\right.$ and $\left.2.4 \pm 0.9 \%\right)$ at this time, but there were no significant differences from that of Day 0 . For lymphocyte and neutrophil, no significant difference was detected between the OVA-treated and control group on Day 18, and between Day 0 and Day 18 in the OVA-treated mice. On Day 21, the eosinophil count showed an increase in the OVA-treated group $\left(1.23 \pm 0.49 \times 10^{5}, 29.5 \pm 8.5 \%\right)$. Then the eosinophil count and percentage rapidly increased and reached maximal values on Day $27\left(7.3 \pm 3.0 \times 10^{5}, 59.6 \pm\right.$ $10.8 \%, p<0.01$ vs those of Day 0 or Day 18). Significant differences in the percentages of eosino-

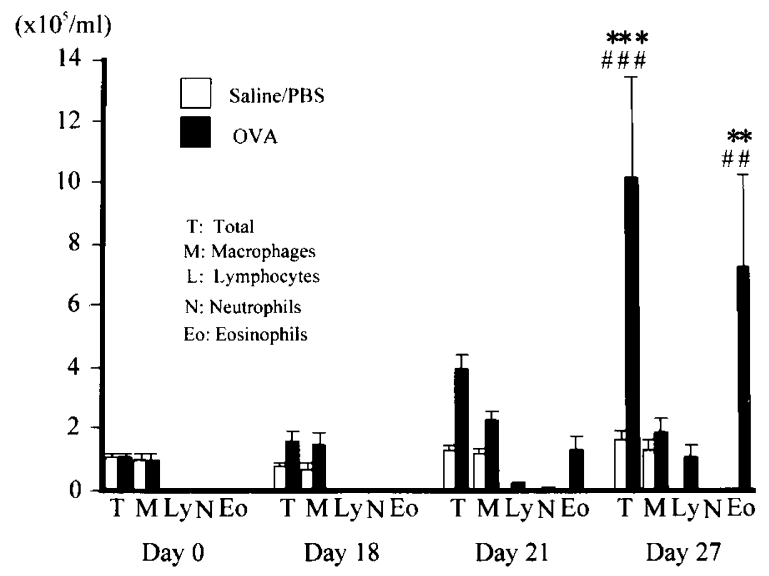

Figure 3.

Change in bronchoalveolar lavage fluid (BALF) differential cell counts following sensitization. Bronchoalveolar lavage (BAL) was carried out according to the time schedule of sensitization in each group of mice. Leukocytes were identified by morphologic criteria. Data represent the mean \pm SEM for groups of seven to eight mice at each time point in both groups. ${ }^{* *} p<0.01$ and ${ }^{* * *} p$

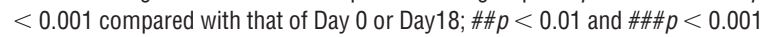
compared with that of the same time point in the control group (ANOVA).

phils were also detected between Day 0 and Day 21, and between Day 18 and Day 21 ( $p<0.01$, for both).

\section{Histologic Findings}

Figure 4 shows representative histologic findings. On Day 18, no abnormal histologic findings were observed in the control mice (Fig. 4A). In the OVA-treated mice, abnormal findings were not observed in most of the samples. However, a very slight degree of infiltration of inflammatory cells into the peribronchial area was detected in some specimens (Fig. 4B). On Day 21, a marked bronchial inflammation was detected in the OVA-treated mice (Fig. 4D). There was an infiltration of inflammatory cells (most of them were eosinophils) into the peribronchial interstitial area and into the mucosal and submucosal areas of the bronchus. A goblet cell formation of bronchial epithelial cells was observed. A bronchoconstriction and a hypertrophy of smooth-muscle cell layer were also observed. In the control group these findings were not observed (Fig. 4C). On Day 27, the intensity of bronchial inflammation was stronger than that on Day 21 in the OVA-treated mice (data not shown). The results obtained from Figures 1 to 4 indicated that an early increase in AHR just after systemic sensitization was induced before the development of airway inflammation and that airway inflammation was induced by repeated OVA inhalation challenges.

\section{Change in Serum IgE}

To study the mechanism(s) leading to the increase in the AHR before the development of prominent airway inflammation, we next analyzed various parameters essential for allergic inflammation. Figure 5 shows the change in the serum IgE concentration at each experimental time point. In the control group, no significant change in $\lg \mathrm{E}$ was detected during the time period of 


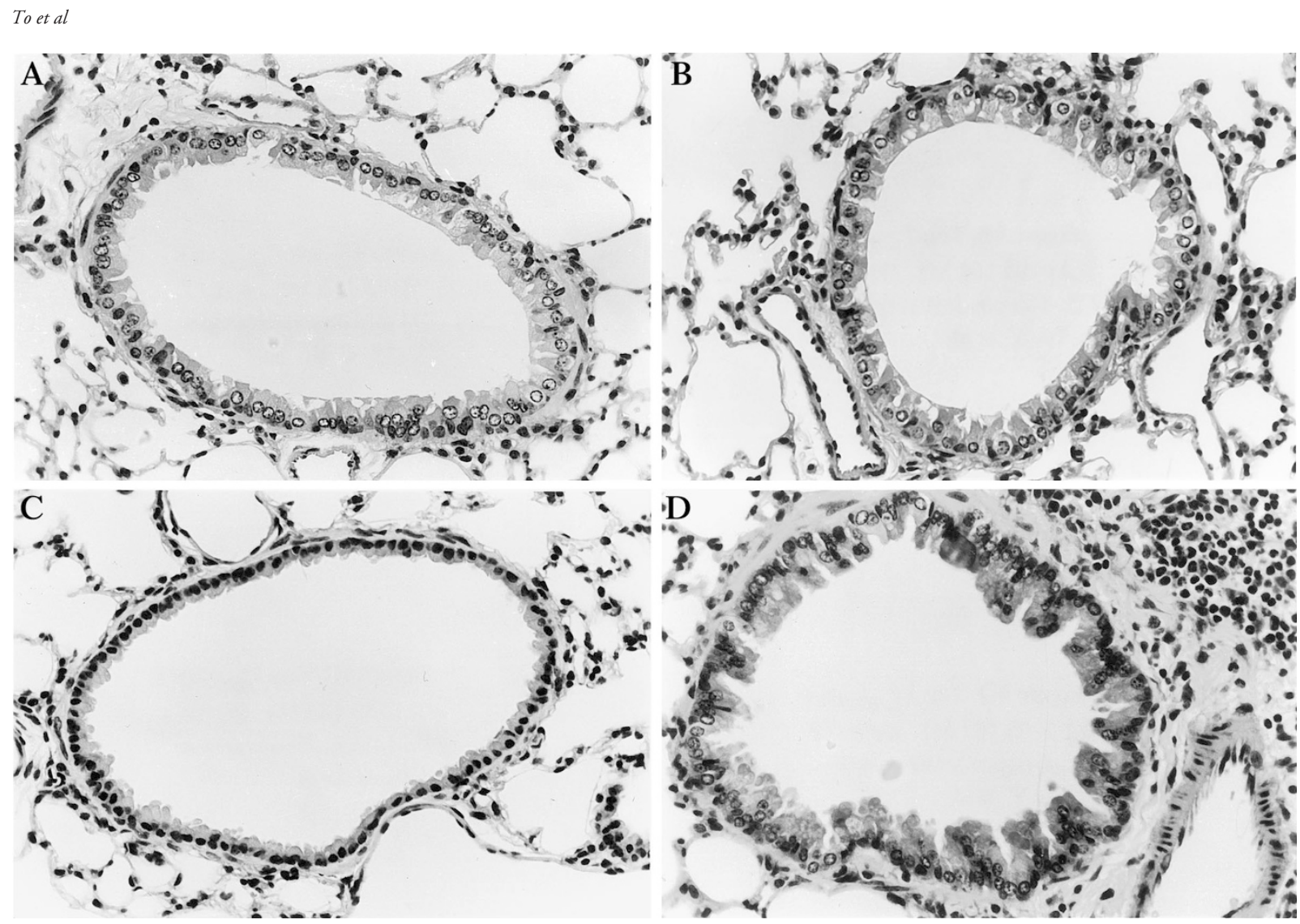

Figure 4.

Histologic findings in the OVA-treated and control mouse. The lung was removed and fixed with $10 \%$ buffered formalin. Samples were then embedded in paraffin, sectioned, and stained with hematoxylin and eosin (H\&E). A, Day 18, control mouse; B, Day 18, OVA-treated mouse; C, Day 21, control mouse; D, Day 21, OVA-treated mouse. One sample is shown and is representative of four to six mice in each group. Magnification, $\times 200$.

$\operatorname{IgE}$

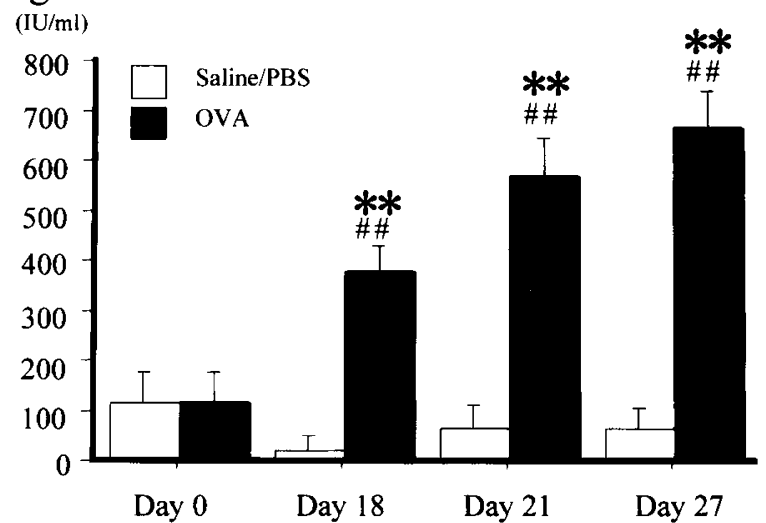

Figure 5.

Change in the serum IgE concentration following sensitization in the OVAtreated group and the control group. Blood samples were obtained from the inferior cava vein at each time point. IgE in the serum was measured by ELISA. Data represent the mean \pm SEM from seven mice per group. ${ }^{\star \star} p<0.01$ compared with baseline value on Day 0 ; \#\# $p<0.01$ compared with $\operatorname{lgE}$ at the same time point in the control group (ANOVA).

the experiment. In the OVA-treated group, IgE increased gradually following the time period. On Day 18 , a significant increase in IgE was already detected. IgE increased further following aerosol sensitization. There were significant differences between the $\lg \mathrm{E}$ value on Day 0 and those values on Day 18, Day 21, and Day 27 ( $p<0.01$, for all three differences).

\section{IL-5, IL-4, and IL-13 Concentrations in BALF}

Next we measured the concentrations of Th2-type cytokines in BALF. The change in IL-5 in BALF (Fig. $6 A)$ showed a tendency similar to that in the eosinophil count in BALF (Fig. 2); namely, it increased along with the OVA inhalation challenges. There was a significant difference in the value between Day 0 and Day $27(p<0.01)$. The changes in the IL-4 concentration showed a different pattern (Fig. 6B). It reached the maximal value on Day 18 , which was significantly higher than the value on Day $0(p<$ 0.01 ) and higher than the value in the control group on the same day $(p<0.01)$. Later on Day 21 , IL-4 decreased, and it remained at almost the same level on Day 27. IL-13 increased gradually following sensitization, peaked in the midst of inhalation challenge (Day 21, $p<0.01$ ), and then slightly decreased (Fig. 6C). No significant changes in the levels of all three cytokines were detected in the control group (Fig. 6, A to C). In both the control and the OVA-treated groups, none of these three cytokines was detected in serum samples by the ELISA system used in this study (data not shown). 
A

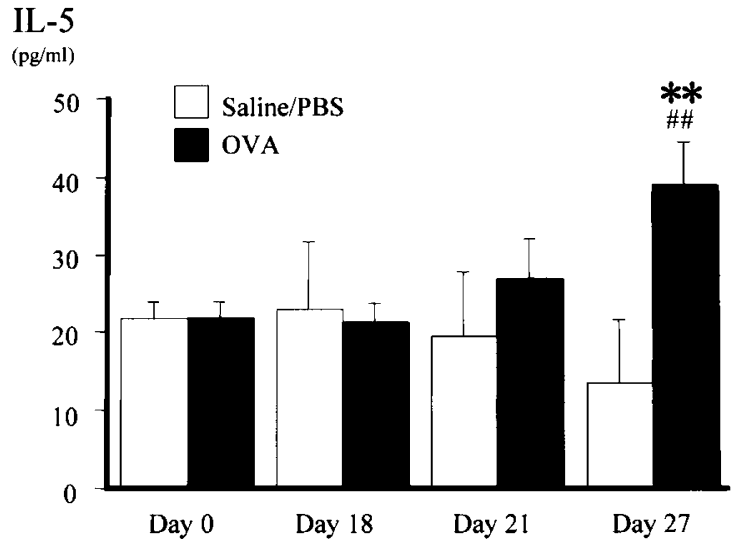

B

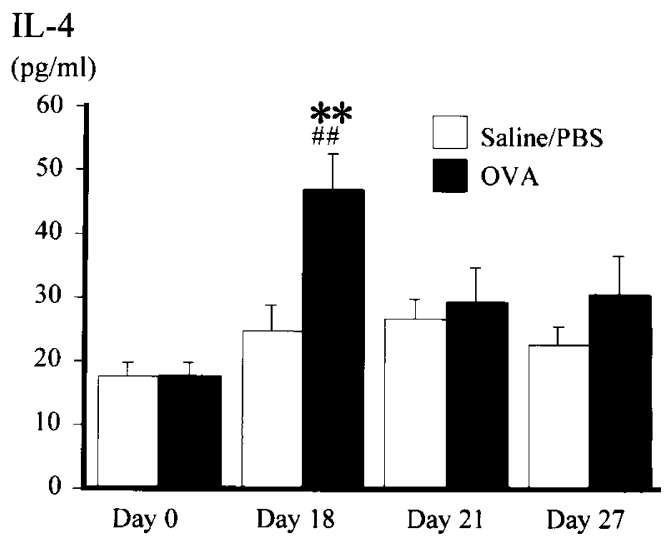

C

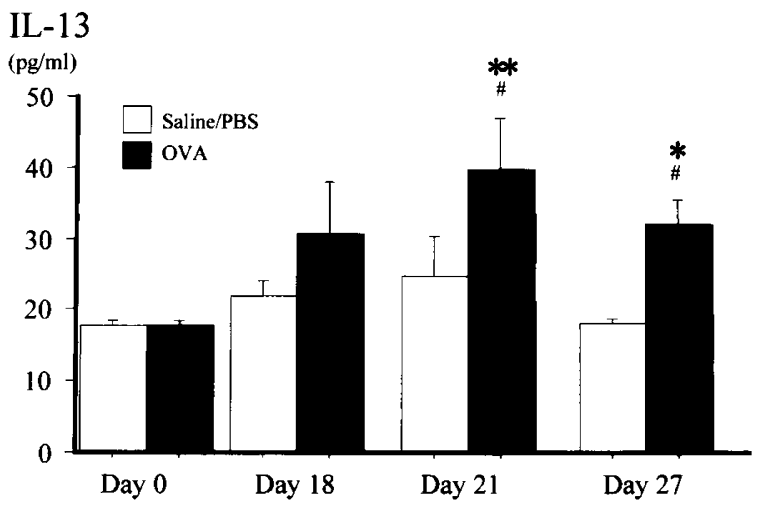

Figure 6.

Change in IL-5, IL-4, and IL-13 concentrations in BALF. At each time point, BAL was performed and then the centrifuged supernatant was assayed for IL-5 (A), IL-4 (B), and IL-13 (C) concentration by ELISA. Data represent the mean \pm SEM for groups of seven mice for each time point in both groups. ${ }^{*} p<0.05$ and ${ }^{* *} p<0.01$ compared with that of Day $0 ; \# p<0.05$ and $\# \# p<0.01$ compared with that of the same time point in the control group (ANOVA). The reproducibility of the result was confirmed by repeating the same experiment four times.

\section{IL-5, IL-4, and IL-13 mRNA Expression in the Lung}

Next we examined whether the discrepancy of expression of these cytokines in BALF could be confirmed at the mRNA level. The expressions of IL-4, IL-5, and
IL-13 in the lung were analyzed by reverse transcriptase-polymerase chain reaction (RT-PCR) (Fig. 7). In the OVA-treated mice, the expression of IL-5 mRNA increased gradually following sensitization. IL-4 mRNA showed the highest expression on Day 18 and then gradually declined. Expression of $\mathrm{IL}-13$ mRNA gradually increased following sensitization, reaching a peak on Day 21 and staying at a similar level until Day 27. In the control mice, no such changes were observed in the levels of either cytokine. These results were basically consistent with the results of protein measurement in the BALF (Fig. 6).

\section{Effect of Anti-IL-4 Antibody Treatment and IL-4 Gene-Targeting on AHR}

The results from BALF analyses and RT-PCR strongly suggested that, among the three Th2 cytokines, IL-4 might play a central role in the early increase in AHR on Day 18. To investigate this possibility, at the last stage of the present study, we examined the effect of inhibition or genetic deletion of IL-4 on the early increase in AHR on Day 18 (Fig. 8). On Day 11, 4 hours after the second injection of OVA allergen, $1 \mathrm{mg}$ of anti-IL-4 neutralizing antibody was injected ip. On Day 18, AHR to Mch and IL-4 concentration in BALF were measured. The antibody treatment effectively abolished the activity of IL-4 in BALF $(13.7 \pm 1.9 \mathrm{pg} / \mathrm{ml}, p$ $<0.01$ compared with the OVA-sensitized group with saline treatment $[46.7 \pm 5.9 \mathrm{pg} / \mathrm{ml}])$. The $\mathrm{PC}_{200}$ Mch of the OVA-sensitized group with saline treatment was $5,635 \pm 583 \mu \mathrm{g} / \mathrm{ml}(n=9)$, whereas $\mathrm{PC}_{200}$ Mch of the OVA-sensitized group that received anti-IL-4 neutralizing antibody was $9,291 \pm 956 \mu \mathrm{g} / \mathrm{ml}(n=6)$. There was a significant difference between the two groups $(p$ $<0.01)$. When the same amount (1 mg) of isotypematched control $\lg _{1}$ was administered instead of neutralizing antibody, no significant suppression in BALF IL-4 and AHR was observed (data not shown). In the saline/PBS control group, $\mathrm{PC}_{200}$ Mch was 10,311 $\pm 1206 \mu \mathrm{g} / \mathrm{ml}(n=8)$. No significant difference was detected between the saline-treated group and the OVA-treated group with anti-IL-4 antibody treatment. Therefore, inhibition of IL-4 in vivo significantly reversed the increase in AHR to near the level of the control saline/PBS-treated group. We also sensitized the IL-4 gene-targeted mice with OVA allergen in the same way as wild-type mice and measured AHR on

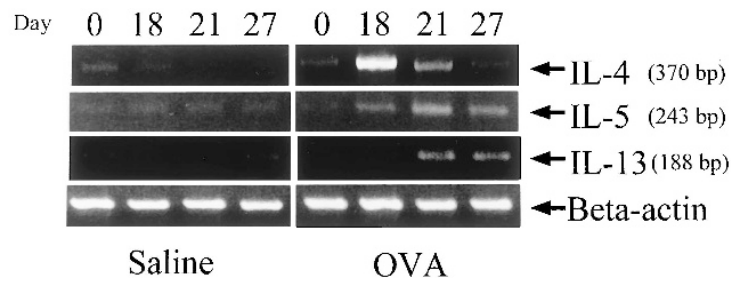

Figure 7.

Messenger RNA expression of IL-4, IL-5, and IL-13 in the lung. After perfusion with physiologic saline, the lung was taken out and total RNA was extracted. After cDNA was synthesized, RT-PCR was carried out as described in "Materials and Methods." Representative figures of four identical experiments are shown. 


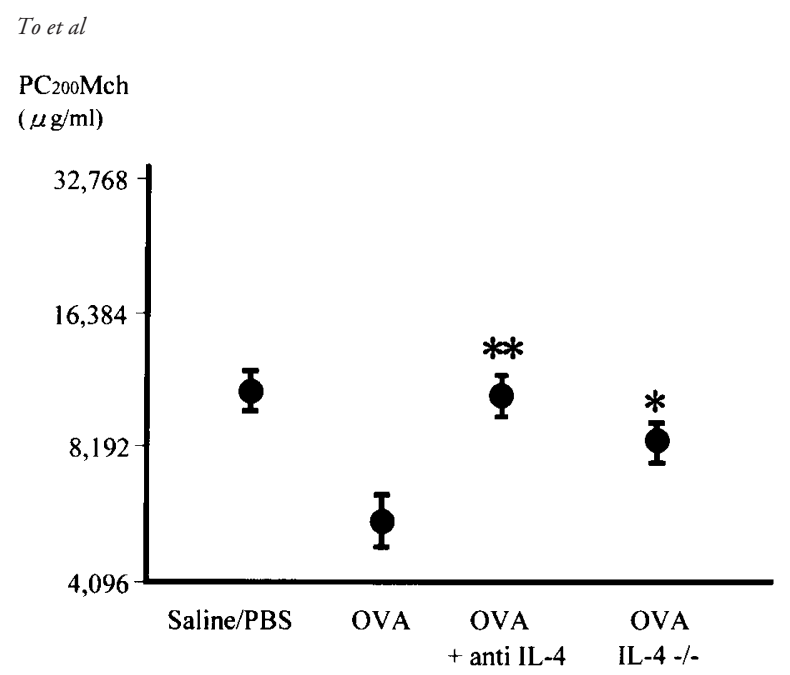

Figure 8.

Effect of treatment with anti-IL-4 neutralizing antibody and IL-4 gene targeting on the early phase AHR. On Day 11, 4 hours after the second systemic sensitization with OVA allergen, $1 \mathrm{mg}$ of anti-IL-4 neutralizing antibody was injected intraperitoneally in designated mice. Control mice received saline injection instead of the antibody. In another group, IL-4 gene-targeted mice were sensitized with the OVA allergen in the same way as wild-type controls. AHR to Mch was measured on Day 18. ${ }^{*} p<0.05$ and ${ }^{* *} p<0.01$ compared with the OVA/saline-treated wild-type mice (ANOVA).

Day 18. The $\mathrm{PC}_{200} \mathrm{Mch}$ of this group of mice on Day 18 was $8,424 \pm 893 \mu \mathrm{g} / \mathrm{ml}(n=6)$. There was a significant difference in AHR between the IL-4 deficient mice and the wild-type mice $(p<0.05)$. No significant difference was detected between saline-treated group and the IL-4 deficient mice. No significant difference in the $\mathrm{PC}_{200} \mathrm{Mch}$ was detected between anti-IL-4treated mice and IL-4 knockout mice $(p=0.4965)$. These results suggested that IL-4 plays an essential role in the early increase in AHR on Day 18 in our experimental system. To clarify the role of IL-13, we measured the IL-13 concentration in BALF in these mice. The concentration of IL-13 was $26.9 \pm 1.7 \mathrm{pg} / \mathrm{ml}$ in saline/PBS mice, $60.9 \pm 8.9 \mathrm{pg} / \mathrm{ml}$ in the OVAtreated mice, $23.8 \pm 0.7 \mathrm{pg} / \mathrm{ml}$ in the OVA-anti-IL-4treated mice, and $23.7 \pm 0.7 \mathrm{pg} / \mathrm{ml}$ in the OVA-treated IL-4 gene-targeted mice. The IL-13 in the OVA-treated mice was higher than that of other groups $(p<0.05)$, but among the other three groups, no significant difference was detected. So IL-13 did not compensate for IL-4 to induce the AHR in a redundant manner.

\section{Discussion}

In this study, we analyzed serial changes in AHR during a time period of systemic and local sensitization and found that AHR could be induced by systemic sensitization alone before the development of airway inflammation in BALB/c mice. This is the first report to focus on the induction of AHR at the very early stage of allergic reaction. Previous analyses of experimental models of asthma have focused mainly on the phase of already developed airway inflammation provoked by repeated systemic and local allergen challenges (Brusselle et al, 1995; Cohn et al, 1998; Corry et al, 1996; Coyle et al, 1995; Dohi et al, 1999; Foster et al,
1996; Grünig et al, 1998; Henderson et al, 1996, 1997; Hogan et al, 1997, 1998a, 1998b; Lilly et al, 1996; Rankin et al, 1996; Wang et al, 1998; Wills-Karp et al, 1998; Zhang et al, 1997b; Zhu et al, 1999). Only a limited number of reports have studied the early phase of the pathophysiologic process. Zhang and coworkers (1997b) reported that ip sensitization with OVA allergen twice, along with one intranasal challenge, can induce airway eosinophilia and AHR. However, they did not study the results with systemic sensitization alone. Tohda and co-workers (2001) reported that a guinea pig treated twice with OVA and alum induced an increased AHR 3 weeks after the second booster injection. However, to induce the AHR with systemic sensitization, they needed cyclophosphamide treatment at the time of the first sensitization. Our study for the first time clearly presented the possibility of an induction of AHR with systemic sensitization alone. In both human cases and animal models of asthma, it is generally considered that the persistence of airway inflammation leads to an increase in AHR. In other words, airway inflammation would be a prerequisite for the induction of AHR in many cases. On the other hand, the dissociation of these two factors sometimes occurs. For example, in clinical patients, even after the intensity of airway inflammation diminishes in response to therapy, AHR sometimes still remains at an increased level. In experimental animals it sometimes happens that airway inflammation can be provoked whereas AHR could not (Lilly et al, 1996; Rankin et al, 1996). Or in other cases, therapeutic approaches such as administering leukotriene inhibitor (Henderson et al, 1996) or antibody to $\alpha 4$-integrin (Henderson et al, 1997) suppressed airway inflammation, but not AHR. However, so far, in all of the previous studies, the coexistence or the dissociation of these two factors has been discussed only for the developed inflammatory phase. Here, we present the possibility that AHR can precede inflammation at a very early stage of sensitization to an allergen in a mouse model. Our results also suggest that systemic sensitization to an allergen may affect the local allergic response in spite of the absence of inflammation at the disease site. A clinical example that might correspond to our current results is that of patients with atopic dermatitis (AD) without any history of asthma, as we previously reported (Dohi et al, 1990). Some AD patients who are highly sensitized to mite allergen already have a moderately to highly increased AHR to acetylcholine regardless of a lack of any history of asthma. In addition, they respond to bronchial provocation with mite allergen and show an immediate asthmatic response. This indicates that once an individual becomes sensitized systemically to an allergen, his (her) airway already might gain the occult reactivity. Recent progress of research on allergy raised a hypothesis that early sensitization and Th2-polarized immunity in infancy may affect the onset of allergic diseases in later life. If this early increase in the AHR observed in mice really does occur in sensitized individuals, it could become a critical predisposing factor leading to onset of asthma later in life, and it 
could be a very important target for prevention of the onset of symptoms as well as for controlling airway inflammation. To study this possibility, AHR in early infancy should be investigated.

In this study IL-4 plays a critical role in the early induction of AHR. The significance of IL-4 in airway inflammation and AHR has been studied in many previous reports (Brusselle et al, 1995; Corry et al, 1996; Coyle et al, 1995). Corry and co-workers (1996) treated mice with anti-IL-4 antibody throughout the experiment, from systemic sensitization to aerosol challenge, or during the period of aerosol challenge only. The former treatment effectively suppressed the AHR observed at the inflammatory phase, whereas the latter did not. Although they observed AHR only in the later inflammatory phase, their result supports the idea that IL-4 in the early phase of sensitization might play an important role in the later development of AHR. Coyle and co-workers (1995) reported the effect of anti-IL-4 antibody administered during sensitization on airway eosinophilia, although they did not observe AHR. In addition to these reports, our results also suggest the significance of IL-4 in the early phase. So far in murine experimental asthma, the relationship between the increase in AHR and key cytokines has been a controversial issue. Some reports emphasize the essential roles of IL-4 in the induction of AHR (Brusselle et al, 1995; Corry et al, 1996; Coyle et al, 1995) and the migration of eosinophils into the airway (Cohn et al, 1998). Other reports support the critical role of IL-5 (Foster et al, 1996; Hogan et al, 1997, 1998a; Lee et al, 1997; Wang et al, 1998). In addition, Hogan and co-workers (1998b) reported a novel $\mathrm{CD} 4+-$ dependent pathway in the BALB/c strain that works independently of both IL-4 and IL-5. Moreover, other recent studies suggest that IL-13, a cytokine that shares the $\alpha$-chain of its receptor complex with IL-4, can alone induce airway inflammation and AHR (Grünig et al, 1998; Wills-Karp et al, 1998; Zhu et al, 1999).

Taking these findings together, we would propose that there are multiple mechanisms or heterogeneity for AHR induction in the BALB/c strain that sometimes work concurrently with each other and sometimes in different phases. One definite pathway is an airway inflammation linked to IL-5 and eosinophilia. Hogan and co-workers (1998a) reported that eosinophils and IL-5 play a central role in the later phase of inflammation and are requisite for pathologic changes in the structure of bronchial tissue, such as bronchoconstriction, mucus edema, and smooth muscle cell hypertrophy. In our data the eosinophil count and IL-5 concentration in the BALF gradually increased following the OVA sensitization, and they paralleled the intensity of histologic findings. So our results, obtained in the later inflammatory phase, were consistent with their findings (Figures 3, 4, 6, and 7). Another potential pathway of AHR induction would be a "preor early- inflammatory" phase that works at an early stage of systemic sensitization to an allergen with little pathologic change in the airway, which we presented in this study. This pathway would work independently of IL-5 and eosinophilia because no increases in IL-5 concentration or eosinophil count were observed at that time in our study (Day 18, Figures 3, 4, 6, and 7). Our results with anti-IL-4 antibody treatment and IL-4 gene-targeted mice strongly suggest that IL-4 plays a pivotal role in this phase (Fig. 8). There was also a slight increase in IL-13 concentration in the BALF on Day 18, although it was not statistically significant (Fig. 6C). So IL-13, another Th2 cytokine, might be partly involved in this pathway.

The cell sources of IL- 4 in the lung at the early phase and the precise mechanism of IL-4-dependent AHR induction also remain unclear at present. We tried to perform histochemical analysis, but it was not successful (data not shown). Instead, in a preliminary study we found that suplatast tosilate, a newly synthesized "Th2 inhibitor" that suppresses the production of $\mathrm{IgE}$ and Th2-type cytokine but not Th1-type cytokine in vitro and in vivo (Shim et al, 2000; Tamaoki et al, 2000; Yamaya et al, 1995; Zhao et al, 2000), suppressed this early increase in AHR on Day 18 (Y To, M Dohi, R Tanaka, K Nakagome, and $\mathrm{K}$ Yamamoto, unpublished data). This result suggests that the pre-/early-inflammatory increase in AHR would be at least partly induced by the Th2 cell-mediated immune response to an allergen. Recently, Haselden and co-workers (1999) reported that $\mathrm{T}$ lymphocyte can directly induce airway response in an IgE-independent manner, which also supports the idea that $T$ cells could directly affect the development of AHR. On the other hand, although there was an increase in IL-4 in BALF on Day 18 , lymphocytes and eosinophils did not increase in BALF, or the infiltration of these inflammatory cells was rare or weak, if present (Figs. 3, 4, and 6). These results indicate that cell sources other than Th2 lymphocytes might contribute to IL-4 production in the lung. Such cells may include mast cells, basophils, antigen-presenting cells such as dendritic cells or macrophages, fibroblasts, endothelial cells, bronchial and alveolar epithelial cells, and so on. In a study using mast-cell-deficient W/Wv mice, Kobayashi and co-workers (2000) recently reported that mast cells also play an important role in the development of AHR induced independently of IL5/eosinophil in the inflammatory phase. In addition, studies with bronchial biopsies from asthmatic patients have demonstrated that both mast cells and $T$ lymphocytes express IL-4 and IL- 5 in the bronchial mucosa (Humbert et al, 1996; Ying et al, 1997). These reports support the possibility that one of the cell sources of IL- 4 in the early phase may be the mast cell. In our results, serum IgE level was already significantly increased on Day 18 (Fig. 5), which also indicates the possibility that mast cells might play some role in the early phase of sensitization. In addition, IgG antibodies and B cell-dependent mechanisms may play some important roles. Furthermore, Lambrecht and co-workers (2000) recently reported that the in vivo transfer of allergenprimed dendritic cells can alone induce Th2 response in the airway, indicating the participation 
of dendritic cells in the process of early sensitization. Moreover, IL-4 may have a direct influence on smooth muscle cells by altering their contractile function via the IL-4 receptor on the cells (Schmidt and Rabe, 2000). Further study, such as with in situ hybridization, should be carried out to clarify the precise cell source and mechanism of the IL-4 production and the IL-4-dependent increase in AHR in the lung. In addition, the role of IL-13, a cytokine that shares the $\alpha$ subunit of its receptor with IL-4, in the mechanism of AHR induction observed in this study should also be further investigated.

In our results, changes in IL-4 showed a different pattern from those in previous reports. In our experiment, IL-4 peaked after systemic sensitization and gradually decreased following aerosol inhalation (Figs. $6 \mathrm{~B}$ and 7). We repeated the same experiment four times and confirmed the reproducibility of the result in our system. On the other hand, in most of the previous studies, IL-4 paralleled the change in IL-5 and usually gradually increased following sensitization (Ohkawara et al, 1997). In the present study, we used $2 \mu \mathrm{g}$ of OVA allergen to immunize the mice, as was done in our previous report (Dohi et al, 1999). This dose was smaller than the dosage used in many previous reports $(8$ to $50 \mu \mathrm{g}$ ). This difference might have affected the results on the expression of IL-4. Our result also showed the dissociation between IL-4 and IL-5, two important Th2 cytokines that play major roles in the induction of allergic inflammation. Generally, the IL-4 and IL-5 genes are coordinately expressed in Th2 cells. However, recent reports have shown another possibility: that the gene expressions of these two cytokines could be regulated differently (Zhang et al, 1997a, 1998). For example, Zhang and co-workers (1997a) reported that while GATA-3 was sufficient for Th2 cell-specific IL-5 expression, IL-4 gene expression seemed to require multiple transcription factors, such as c-Maf (Ho et al, 1996), NF-ATc (Yoshida et al, 1998), or NF-IL-6 (Davydov et al, 1995), that might act in concert with GATA-3 (Ray and Cohn, 1999). Therefore, in our experimental mice, different transcription factors might have been activated at different time points in the experiment. Moreover, the relationship in the transcriptional control between IL-4 and IL-13 has not been well elucidated so far and should be further investigated.

In conclusion, our data suggest the heterogeneity of the mechanisms that induce AHR. As well as airway inflammation, early IL-4-dependent immune response alone can induce an increase in AHR in $\mathrm{BALB} / \mathrm{c}$ mouse model. If this mechanism also works in humans who are sensitized to allergen(s) in an early stage of their lives, it might induce AHR and thus become a critical predisposing factor for onset of asthmatic symptoms later in life. Therefore, it could be an important therapeutic target for the prevention of future onset of asthma.

\section{Materials and Methods}

\section{Reagents}

Chicken egg albumin (ovalbumin: OVA; grade V) and methacholine chloride (Mch) were purchased from Sigma (St. Louis, Missouri). PBS was from GIBCO BRL Life Technologies, Inc. (Grand Island, New York). Sodium pentobarbital was from Dainippon Chemicals (Osaka, Japan). Neutralized formalin, Türk solution, and BSA were from Wako Pure Chemical Industries, Ltd. (Osaka, Japan). Trypan-blue and Diff-Quick staining solutions were from Kokusai-Shiyaku Company, Ltd. (Kobe, Japan). The superscript preamplification system for first-strand cDNA synthesis was from Life Technologies, Inc. (Gaithersburg, Maryland). The multiplex PCR (MPCR) Kit for mouse TH1/TH2 cytokines, the primer set for mouse IL-5, and the primer set for mouse $\beta$-actin were obtained from Maxim Biotech, Inc. (San Francisco, California). The ELISA kit for mouse IgE was obtained from Yamasa Soy-Sauce Breweries Company, Ltd. (Chiba, Japan). The mouse ELISA kits for IL-4, IL-5, and IL-13 were from BioSource International, Inc. (Camarillo, California), PerSeptive Diagnostics, Inc. (Cambridge, Massachusetts), and R\&D systems (Minneapolis, Minnesota), respectively. The neutralizing antibody to $\mathrm{IL}-4$ and the lgG1 isotype control (mouse purified monoclonal lgG) were from Genzyme Techne (Minneapolis, Minnesota).

\section{Animals}

Male BALB/cAnNCrj mice ( 6 weeks of age) were obtained from Charles River Japan, Inc. (Kanagawa, Japan). IL-4 gene-deleted mice (BALB/C-IL4 ${ }^{\text {tm2Nnt, }}$ male, 6 weeks of age) were obtained from the Jackson Laboratory (Bar Harbor, Maine). They were maintained under conventional animal housing conditions in a specific pathogen-free setting. All of the animal experiments carried out in this study were approved by the Animal Research Ethics Board of the Department of Allergy and Rheumatology, University of Tokyo.

\section{Immunization of Mice}

The mice were immunized as reported previously (Dohi et al, 1999). Seven-week-old animals were immunized by a combination of OVA $(2 \mu \mathrm{g})$ and alum ( 2 $\mathrm{mg}$ ) by ip injection on Day 0 , and then again on Day 11. Control mice received saline injection instead of the OVA/alum solution. On Day 18, an aerosolized solution of $3 \%$ OVA diluted in PBS was administered. The aerosolized solution was produced by a DeVilbiss Pulmo-Aide compressor/nebulizer (DeVilbiss Corporation, Somerset, Pennsylvania) for 10 minutes. OVA inhalation was carried out for 5 consecutive days. Control mice were subjected to PBS inhalation under the same conditions. Ninety-six hours after the fifth OVA challenge (on Day 26), a final OVA inhalation challenge (the sixth OVA challenge) was given in the same way, and the control group was challenged with PBS. Experimental data were obtained according to the experimental protocol on Day 0 (before the first 
systemic immunization), Day 18 (1 week after the second systemic immunization and just before the first aerosol inhalation), Day 21 (24 hours after the third aerosol challenge), and Day 27 (24 hours after the final OVA provocation).

\section{Measuring Bronchial Response with the Penh System}

Following the sensitization, bronchial response was measured in unrestrained, spontaneously breathing mice through barometric whole-body plethysmography (Jacky, 1978) using the Biosystem XA WBP system (Buxco, Troy, New York) as reported previously from many laboratories including ours (Dohi et al, 1999; Hamelmann et al, 1997; Lee et al, 1997; Schwarze et al, 1997). Briefly, mice were placed in the main chamber (animal chamber) of the plethysmograph, and the pressure differences (termed the box pressure signal) between this chamber and a reference chamber integral to the main chamber were measured with a differential pressure transducer connected to the amplifier. From the box pressure signal, the phases of the respiratory cycle, tidal volumes, and Penh can be calculated. Penh is a dimensionless value that represents a function of the proportion of maximal expiratory to maximal inspiratory box pressure signals and of the timing of expiration. According to the manufacturer's instructions, Penh was calculated as follows:

$(T e-\operatorname{Tr}) / \operatorname{Tr}$ (defined as "pause") $\times(\mathrm{PEF} / \mathrm{PIP})$,

where $\mathrm{Te}=$ expiratory time (seconds); $\mathrm{Tr}=$ relaxation time (seconds), defined as the time of pressure decay to $30 \%$ of the total expiratory pressure signal (area under the box pressure signal at expiration); PEF = peak expiratory flow $(\mathrm{ml} / \mathrm{second})$; and PIP = peak inspiratory flow ( $\mathrm{ml} / \mathrm{second})$. Penh reflects changes in the waveform of the box pressure signal during both inspiration and expiration, and combines these changes with the timing comparison of early and late expiration (pause). Once the mouse was placed in the main chamber, recordings were continued for 3 minutes. Penh was measured and averaged approximately every 5 seconds, and the cumulative values were averaged and expressed as Penh for each time point (Dohi et al, 1999).

\section{Measuring AHR to Methacholine}

Nonspecific AHR to Mch was measured with the Penh system essentially following the method reported by Lee and co-workers (1997). Briefly, the baseline Penh value was first recorded. Then, after confirming that Penh did not increase with an inhalation of physiologic saline, increasing concentrations of Mch (1000, 3000, $10,000,20,000$, and $30,000 \mu \mathrm{g} / \mathrm{ml}$ in physiologic saline) were delivered by the nebulizer for 2.5 minutes. Penh was recorded for 2.5 minutes just after each inhalation. The concentration of Mch that induced a $100 \%$ increase in Penh $(200 \%$ over the baseline value obtained by saline challenge) was calculated from the semi-log scale dose-response curve and expressed as $\mathrm{PC}_{200} \mathrm{Mch}(\mu \mathrm{g} / \mathrm{ml})$ as an indicator of AHR.

\section{Bronchoalveolar Lavage Fluid Analyses}

After measuring the Penh, bronchoalveolar lavage (BAL) samples were obtained. The mice were anesthetized by ip injection of sodium pentobarbital (50 60 $\mathrm{mg} / \mathrm{kg}$ body weight). Then the lungs were lavaged four times with physiologic saline $(0.5 \mathrm{ml}$ each). Approximately $1.6 \mathrm{ml}$ of the instilled saline was consistently recovered with gentle handling. The cell suspension was centrifuged at $300 \times g$ for 10 minutes at $4^{\circ} \mathrm{C}$. The supernatants were collected and stored at $-70^{\circ} \mathrm{C}$ until measurement of IL-4, IL-5, and IL-13. The cells were resuspended in $1 \mathrm{ml}$ of saline with $1 \% \mathrm{BSA}$, and the total cell numbers were counted with a hemocytometer. Cytospin samples were prepared by centrifuging the suspensions $(100$ or $150 \mu l)$ at $300 \mathrm{rpm}$ for 10 minutes. To clearly distinguish eosinophils from the neutrophils, three different stains were applied: DiffQuick stain, May-Grünwald-Giemsa stain, and Eosino (Hansel) stain (Dohi et al, 1999). On the basis of the findings with these stainings, cell differentials were counted with at least 300 leukocytes in each sample. The cell types were judged according to standard hemocytologic procedures as neutrophils, eosinophils, lymphocytes, or other mononuclear leukocytes (macrophages and monocytes).

\section{Lung Tissue and Histologic Examination}

After perfusion with physiologic saline, the lungs were taken from the experimental mice, fixed with neutralized buffered formalin, and embedded in paraffin. Three-micrometer-thick sections were stained with hematoxylin and eosin (H\&E).

\section{Measuring Total IgE}

Blood samples were obtained from some of the mice, and the sera were assayed for total IgE concentration (Dohi et al, 1999). After the mice were anesthetized, the abdominal wall was dissected. A blood sample was obtained with a 26-gauge needle from the inferior cava vein. After the samples had fully coagulated, they were centrifuged ( $2000 \times g$ for 20 minutes at $4^{\circ} \mathrm{C}$ ), and the sera were collected and stored at $-70^{\circ} \mathrm{C}$ until use. Total IgE was measured with an ELISA system. Briefly, plates were first precoated with sheep anti-mouse lgE, then a serum sample (100 $\mu$ l each) or mouse lgE standard was added, and the plates were incubated for 30 minutes at room temperature (RT) and washed. Next, a monoclonal anti-mouse $\operatorname{lgE}$ antibody was added and the plates were incubated for 30 minutes at RT and washed. Finally, substrate solution was added, and the reaction was stopped after 15 minutes. Absorbance was analyzed at $450 \mathrm{~nm}$ with a Microplate Reader (Bio-Rad Laboratories, Hercules, California), and data were analyzed with Microplate Manager III, Version 1.45 (Bio-Rad Laboratories).

\section{Measuring IL-4, IL-5, and IL-13 in BALF}

Concentrations of IL-4, IL-5, and IL-13 in BALF were measured using the ELISA kit, following the manufac- 
ture's protocol. Briefly, flat-bottomed immunoassay plates were precoated with rat anti-mouse IL-4 mAb, with rat anti-mouse IL-5 mAb, or with rat anti-mouse $\mathrm{IL}-13 \mathrm{mAb}$, and then incubated with nondiluted BALF, serum samples, or standard murine IL-4, IL-5, and IL-13. Murine IL-4, IL-5, and IL-13 were detected with a rabbit anti-mouse IL-4, IL-5, and IL-13 mAb, respectively. After incubating the plates with a streptavidinconjugated alkaline phosphatase solution for 2 hours at $37^{\circ} \mathrm{C}$, they were washed, and an alkaline phosphatase substrate solution was added. The reactions were stopped with $1 \mathrm{~N} \mathrm{HCl}$. A Microplate Reader at $450 \mathrm{~nm}$ measured the plates, and the data were analyzed with Microplate Manager III, Version 1.45.

\section{Extraction of RNA from Lung and RT-PCR}

In some of the experimental groups, the lung was removed after perfusion with physiologic saline, and RNA was extracted immediately by the acidguanidium phenol chloroform (AGPC) method. Two micrograms of total RNA was used for cDNA synthesis with reverse transcriptase using oligo $\mathrm{dT}$ primer for each lung sample. Each cDNA sample was subjected to PCR. PCR conditions were optimized for linear amplification to allow direct comparison between samples. The primer set in the MPCR Kit was used to amplify the IL-4 gene. PCR was carried out with $\times 1$ PCR gold buffer (PE Applied Biosystems, Foster City, California), $1.5 \mathrm{~mm} \mathrm{MgCl}_{2}$, $2.5 \mathrm{~mm}$ of each dNTP, and 0.25 unit of Amplitaq Gold DNA polymerase. The reaction was performed with the Gene Amp PCR System 9700 (PE Applied Biosystems) for 30 cycles (35 cycles for IL-13) with denaturation/annealing/extension conditions optimal to each primer set: IL-4 $\left(94^{\circ} \mathrm{C}\right.$ for 1 minute for denaturation, and $59^{\circ} \mathrm{C}$ for 5 minutes for annealing and extension); IL- 5 and $\beta$-actin $\left(94^{\circ} \mathrm{C}\right.$ for 1 minute for denaturation, $58.5^{\circ} \mathrm{C}$ for 1 minute for annealing, and $72^{\circ} \mathrm{C}$ for 1 minute for extension); IL-13 (94 ${ }^{\circ} \mathrm{C}$ for 30 seconds for denaturation, $66^{\circ} \mathrm{C}$ for 30 seconds for annealing, and $72^{\circ} \mathrm{C}$ for 40 seconds for extension). The sense primer for IL-5 was 5'-ATGACTGTGCCTCTGTGCCTGGAGC-3', and the antisense primer was 5'-CTGTTTTTCCTGGAGTAAACTGGGG-3'. The sense primer for IL-13 was 5'-GCCAGCCCACAGTTCTACAGC-3', and the antisense primer was 5'-GTGATGTTGCTCAGCTCCTCA-3' (Todt et al, 2000). The sense primer for $\beta$-actin was 5'-TGGAATCCTGTGGCATCCATGAAAC-3', and the antisense primer was 5'-TAAAACGCAGCTCAGTAACAGTCCG-3'. PCR products were electrophoresed in a $3 \%$ agarose gel. The results were visualized by ethidium bromide staining and analyzed by Adobe PhotoDeluxe 2.0.1N (Adobe Systems, Inc., San-Jose, California).

\section{Treatment of Mice with Anti-IL-4 Antibody}

On Day 11, 4 hours after the second injection of OVA allergen, $1 \mathrm{mg}$ of anti-IL-4 neutralizing antibody was injected ip. Seven days later, on Day 18, measurements were taken to determine the IL-4 concentration in BALF and AHR to Mch. As a control, physiologic saline alone or the same amount of isotope-matched mouse IgG1 was injected.

\section{Statistical Analysis}

Data are expressed as the mean \pm SEM. The significance of data was analyzed with the StatView, Version 4.5J, software system (SAS Corporation, Cary, North Carolina) and evaluated using two-way analysis of variance (ANOVA) followed by the Student's $t$ test for comparison between two groups. A probability value ( $p$ value) of less than 0.05 was considered statistically significant.

\section{Acknowledgement}

The authors thank Ms. Mayumi Katakawa and Ms. Eri Ogawa for their technical assistance.

\section{References}

Borish L, Aarons A, Rumbert J, Cvietusa P, Negri J, and Wenzel S (1996). Interleukin-10 regulation in normal subjects and patients with asthma. J Allergy Clin Immunol 97:12881296.

Brusselle G, Kips J, Joos G, Bluethmann H, and Pauwels R (1995). Allergen-induced airway inflammation and bronchial responsiveness in wild-type and interleukin-4-deficient mice. Am J Respir Cell Mol Biol 12:254-259.

Burrows B, Martinez FD, Halonen M, Barbee R, and Cline MG (1989). Association of asthma with serum IgE levels and skin prick test reactivity to allergens. N Engl J Med 320:271-277.

Cohn L, Tepper JF, and Bottomly K (1998). IL-4-independent induction of airway hyperresponsiveness by Th2, but not Th1 cells. J Immunol 161:3813-3816.

Corry DB, Folkesson HG, Warnock ML, Erle DJ, Matthay MA, Wiener-Kronish JP, and Locksley RM (1996). Interleukin 4, but not interleukin 5 or eosinophils, is required in a murine model of acute airway hyperreactivity. J Exp Med 183:109117.

Coyle AJ, Le Gros G, Bertland C, Tsuyuki S, Heusser CH, Kopf M, and Anderson GP (1995). Interleukin-4 is required for the induction of lung Th2 mucosal immunity. Am J Respir Cell Mol Biol 13:54-59.

Crimi E, Gaffi D, Frittili E, Borgonovo B, and Burastero SE (1997). Depletion of circulating allergen-specific TH2 T lymphocytes after allergen exposure in asthma. J Allergy Clin Immunol 99:788-797.

Davydov IV, Krammer PH, and Li-Weber M (1995). Nuclear factor-IL-6 activates the human IL-4 promoter in T cells. J Immunol 155:5273-5279.

De Sanctis GT, Itoh A, Green FHY, Quin S, Kimura T, Grobholz JK, Martin TR, Maki T, and Drazen JF (1997). T-lymphocytes regulate genetically determined airhyperresponsiveness in mice. Nat Med 3:460-462.

Dohi $M$, Okudaira $H$, Sugiyama $H$, Tsurumachi $N$, Suko $M$, Nakagawa T, Morita $\mathrm{Y}$, Ito $\mathrm{K}, \mathrm{Nakayama} \mathrm{H}$, and Miyamoto $\mathrm{T}$ (1990). Bronchial responsiveness to mite allergen in atopic dermatitis without asthma. Int Arch Allergy Appl Immunol 92:138-142. 
Dohi M, Tsukamoto S, Nagahori T, Shinagawa K, Saitoh K, Tanaka Y, Kobayashi S, Tanaka R, To Y, and Yamamoto K (1999). Noninvasive system for evaluating the allergenspecific airway response in a murine model of asthma. Lab Invest 79:1559-1571

Foster PS, Hogan SP, Ramsay AJ, Matthaei KI, and Young IG (1996). Interleukin 5 deficiency abolishes eosinophilia, airway hyperreactivity, and lung damage in a mouse asthma model. J Exp Med 183:195-201.

Gern JE, Lemanske RF, and Busse WW (1999). Early life origins of asthma. J Clin Invest 104:837-843.

Grünig G, Warnock M, Wakil AE, Venkayya R, Brombacher F, Rennick DM, Sheppard D, Mohrs M, Donaldson DD, Locksley RM, and Corry DB (1998). Requirement for IL-13 independently of IL-4 in experimental asthma. Science 282:22612263.

Hamelmann E, Schwartz J, Takeda K, Oshiba A, Larsen GL, Irvin CG, and Gelfand EW (1997). Noninvasive measurement of airway responsiveness in allergic mice using barometric plethysmography. Am J Respir Crit Care Med 156:766-775.

Hansen G, Berry G, DeKruyff RH, and Umetsu DT (1999). Allergen-specific Th1 cells fail to counterbalance Th2 cellinduced airway hyperreactivity but cause severe airway inflammation. J Clin Invest 103:175-183.

Haselden BM, Kay AB, and Larché M (1999). IgEindependent MHC-restricted T cell peptide epitope-induced late asthmatic response. J Exp Med 189:1885-1894.

Henderson WR Jr, Chi EY, Albert RK, Chu S-J, Lamm WJE, Rochon, Y, Joans I, Christie PE, and Harian JM (1997). Blockade of CD49d ( $\alpha 4$ integrin) on pulmonary but not circulating leukocytes inhibits airway inflammation and hyperresponsiveness in a mouse model of asthma. J Clin Invest 100:3083-3092.

Henderson WR Jr, Lewis DB, Albert RK, Zhang Y, Lamm JE, Chiang GKS, Jones F, Eriksen $\mathrm{P}$, Tien $\mathrm{Y}-\mathrm{T}$, Joans $\mathrm{M}$, and Chi EY (1996). The importance of leukotrienes in airway inflammation in a mouse model of asthma. J Exp Med 184:14831494.

Ho IC, Hodge MR, Rooney JW, and Glimcher LH (1996). The proto-oncogene c-maf is responsible for tissue-specific expression of interleukin-4. Cell 85:973-983.

Hogan SP, Koskinen A, Matthaei KI, Young IG, and Foster PS (1998a). Interleukin-5-producing CD4 + T cells play a pivotal role in aeroallergen-induced eosinophilia, bronchial hyperreactivity, and lung damage in mice. Am J Respir Crit Care Med 157:210-218.

Hogan SP, Matthaei KI, Young JM, Koskinen A, Young IG, and Foster PS (1998b). A novel T cell-regulated mechanism modulating allergen-induced airways hyperreactivity in BALB/c mice independently of IL-4 and IL-5. J Immunol 161:1501-1509.

Hogan SP, Mould A, Kikutani H, Ramsay AJ, and Foster PS (1997). Aeroallergen-induced eosinophilic inflammation, lung damage, and airway hyperreactivity in mice can occur independently of IL-4 and allergen-specific immunoglobulins. $\mathrm{J}$ Clin Invest 99:1329-1339.

Holt PG, Macaubas C, Stumbles PA, and Sly PD (1999). The role of allergy in the development of asthma. Nature 402(Suppl):B12-B17.

Humbert M, Durham SR, Kimmitt P, Powell N, Assoufi B, Pfister R, Mentz G, Kay AB, and Corrigan CJ (1997). Elevated expression of messenger ribonucleic acid encoding IL-13 in the bronchial mucosa of atopic and nonatopic subjects with asthma. J Allergy Clin Immunol 99:657-665.

Humbert M, Durham SR, Ying S, Kimmitt $P$, Barkans J, Assoufi B, Pfister R, Menz G, Robinson DS, Kay AB, and Corrigan CJ (1996). IL-4 and IL-5 mRNA and protein in bronchial biopsies from patients with atopic and nonatopic asthma: Evidence against "asthma being a distinct immunological entity." Am J Respir Crit Care Med 154:1497-1504.

Jacky JP (1978). A plethysmograph for long-term measurement of ventilation in unrestrained animals. J Appl Physiol 45:644-647.

Kobayashi T, Miura T, Haba T, Sato M, Serizawa I, Nagai H, and Ishizaka K (2000). An essential role of mast cells in the development of airway hyperresponsiveness in a murine asthma model. J Immunol 164:3855-3861.

Lambrecht BN, De Veerman M, Coyle AJ, Gutierrez-Ramos J-C, Thilemans K, and Pauwels RA (2000). Myeloid dendritic cells induce Th2 responses to inhaled antigen, leading to eosinophilic airway inflammation. J Clin Invest 106:551-559.

Lamkhioued B, Renzi PM, Abi Younes S, Garcia Zepada EA, Allakhverdi Z, Ghaffar O, Rothenberg MD, Luster AD, and Hamid Q (1997). Increased expression of eotaxin in bronchoalveolar lavage and airways of asthmatics contributes to the chemotaxis of eosinophils to the site of inflammation. J Immunol 159:4593-4601.

Lee JJ, McGarry MP, Farmer SC, Denzler KL, Larson KA, Carrigan PE, Brenneise IE, Horton MA, Haczku A, Gelfand EW, Leikauf GD, and Lee NA (1997). Interleukin-5 expression in the lung epithelium of transgenic mice leads to pulmonary changes pathognomonic of asthma. J Exp Med 185:21432156.

Leonard C, Tormey V, Burke C, and Poulter LW (1997). Allergen-induced cytokine production in atopic disease and its relationship to disease severity. Am J Respir Cell Mol Biol 17:368-375.

Lilly CM, Chapman RW, Sehring SJ, Mauser PJ, Egan RW, and Drazen, JM (1996). Effects of interleukin 5-induced pulmonary eosinophilia on airway reactivity in the guinea pig. Am J Physiol 270:L368-L375.

Ohkawara Y, Lei X-F, Stämpfli MR, Marshall JS, Xing Z, and Jordana M (1997). Cytokine and eosinophil responses in the lung, peripheral blood, and bone marrow compartments in a murine model of allergen-induced airways inflammation. Am J Respir Cell Mol Biol 16:510-520.

Randolph DA, Carruthers CJL, Szabo SJ, Murphy KM, and Chaplin DD (1999a). Modulation of airway inflammation by passive transfer of allergen-specific Th1 and Th2 cells in a mouse model of asthma. J Immunol 162:2375-2383.

Randolph DA, Stephens R, Carruthers CJL, and Chaplin DD (1999b). Cooperation between Th1 and Th2 cells in a murine model of eosinophilic airway inflammation. J Clin Invest 104:1021-1029.

Rankin JA, Picarella DE, Geba GP, Temann UA, Prasad B, Discosmo B, Tarallo A, Stripp B, Whisett J, and Flavell RA (1996). Phenotypic and physiologic characterization of transgenic mice expressing interleukin 4 in the lung: Lymphocytic and eosinophilic inflammation without airway hyperreactivity. Proc Natl Acad Sci USA 93:7821-7825. 
Ray A and Cohn L (1999). Th2 cells and GATA-3 in asthma: New insights into the regulation of airway inflammation. J Clin Invest 104:985-1006.

Robinson DS, Tsicopoulos A, Meng Q, Durham S, Kay AB, and Hamid Q (1996). Increased interleukin-10 messenger RNA expression in atopic allergy and asthma. Am J Respir Cell Mol Biol 14:113-117.

Schmidt D and Rabe KF (2000). Immune mechanisms of smooth muscle hyperreactivity in asthma. J Allergy Clin Immunol 105:673-682.

Schwarze J, Hamelmann E, Bradley KL, Takeda K, and Gelfand EW (1997). Respiratory syncytial virus infection results in airway hyperresponsiveness and enhanced airway sensitization to allergen. J Clin Invest 100:226-233.

Sears MR, Burrows B, Flanner E M, Herbinson GP, Hewitt CJ, and Holdaway MD(1991) Relationship between airway responsiveness and serum IgE in children with asthma and in apparently normal children. N Engl J Med 325:10671071.

Shi HZ, Deng JM, Xu H, Nong ZX, Xiao CQ, Liu ZM, Qin SM, Jiang HX, Liu GN, and Chen YQ (1998a). Effect of inhaled interleukin-4 on airway hyperreactivity asthmatics. Am J Respir Crit Care Med 157:1818-1821.

Shi HZ, Xiao CQ, Zhong D, Qin SM, Liu Y, Liang G, Xu H, Chen YQ, Long XM, and Xie ZF (1998b). Effect of inhaled interleukin-5 on airway hyperreactivity and eosinophilia in asthmatics. Am J Respir Crit Care Med 157:204-209.

Shim JJ, Dabbagh K, Takeyama K, Burgel PR, Dao-Pick TP, Ueki IF, and Nadel JA (2000). Suplatast tosilate inhibits goblet-cell metaplasia of airway epithelium in sensitized mice. J Allergy Clin Immunol 105:739-745.

Tamaoki J, Kondo M, Sakai N, Aoshiba K, Tagaya E, Nakata J, Isono K, and Nagai A (2000). Effect of suplatast tosilate, a Th2 cytokine inhibitor, on steroid-dependent asthma: a double-blind randomized study. Lancet 356: 273-278.

Till SJ, Durham SR, Rajakulasingam K, Humbert M, Huston D, Dickason R, Kay AB, and Corrigan CJ (1998). Allergeninduced proliferation and interleukin- 5 production by bronchoalveolar lavage and blood T cells after segmental allergen challenge. Am J Respir Crit Care Med 158:404-411.

Todt J, Sonstein J, Polak T, Seitzman GD, Hu B, and Curtis $\mathrm{JL}$ (2000). Repeated intratracheal challenge with particulate antigen modulates murine lung cytokines. J Immunol 164: 4037-4047.

Tohda Y, Muraki M, Kubo H, Itoh M, Haraguchi R, Nakajima $S$, and Fukuoka M (2001). Role of chemical mediators in airway hyperresponsiveness in an asthmatic model. Respiration 68:73-77.

Van Der Pouw Kraan TCTM, Boeije LCM, de Groot ER, Stapel SO, Snijders A, Kapsenberg ML, van der Zee JS, and Aarden LA (1997). Reduced production of IL-12 and IL-12dependent IFN- $\gamma$ release in patients with allergic asthma. $\mathrm{J}$ Immunol 158:5560-5565.
Wang J, Palmer K, Lotvall J, Milans S, Lei XF, Matthaei K, Gauldie J, Inman MD, Jordana M, and Xing Z (1998). Circulating, but not local lung, IL-5 is required for the development of antigen-induced airways eosinophilia. J Clin Invest 102: $1132-1141$

Wills-Karp M, Luyimbazi J, Xu X, Schofield B, Neben TY, Karp CL, and Donaldson DD (1998). Interleukin-13: Central mediator of allergic asthma. Science 282:2258-2261.

Yamaya H, Basaki $Y$, Togawa M, Kojima M, Kiniwa M, and Matsuura N (1995). Down-regulation of Th2 cell-mediated murine peritoneal eosinophilia by antiallergic agents. Life Sci 56:1647-1654.

Ying S, Humbert M, Barkans J, Corrigan CJ, Pfister R, Menz G, Larche M, Robinson D S, Durham SR, and Kay AB (1997). Expression of IL-4 and IL-5 mRNA and protein product by CD4+ and CD8+ T cells, eosinophils, and mast cells in bronchial biopsies obtained from atopic and nonatopic (intrinsic) asthmatics. J Immunol 158:3539-3544.

Yoshida H, Nishina H, Takimoto H, Marengere LE, Wakeham AC, Bouchard D, Kong YY, Ohtaki T, Shahinian A, Bachmann M, Ohashi PS, Penninger JM, Crabtree GR, and Mak TW (1998). The transcription factor NF-ATc 1 regulates lymphocyte proliferation and Th2 cytokine production. Immunity 8:115-124.

Zhang D-H, Cohn L, Ray P, Bottomly K, and Ray A (1997a). Transcription factor GATA-3 is differentially expressed in murine Th1 and Th2 cells and controls Th2-specific expression of the interleukin-5 gene. J Biol Chem 272:2159721603.

Zhang D-H, Yang L, and Ray A (1998). Differential responsiveness of the IL-5 and IL-4 genes to transcription factor GATA-3. J Immunol 161:3817-3821.

Zhang YU, Lamm WJE, Albert RK, Chi EY, Henderson WR Jr, and Lewis DB (1997b). Influence of the route of allergen administration and genetic background on the murine allergic pulmonary response. Am J Respir Crit Care Med 155:661669.

Zhao G, Yokoyama A, Kohno N, Hamada H, and Hiwada K (2000). Effect of suplatast tosilate (IPD-1151T) on a mouse model of asthma: Inhibition of eosinophilic inflammation and bronchial hyperresposiveness. Int Arch Allergy Immunol 121: 116-122.

Zhu Z, Homer RJ, Wang Z, Chen Q, Geba GP, Wang J, Zang $Y$, and Elias J A (1999). Pulmonary expression of interleukin-13 causes inflammation, mucus hypersecretion, subepithelial fibrosis, physiologic abnormalities, and eotaxin production. J Clin Invest 103:779-788. 